Check for updates

Cite this: RSC Adv., 2019, 9, 21498

Received 14th May 2019

Accepted 1st July 2019

DOI: $10.1039 / c 9 r a 03629 f$

rsc.li/rsc-advances

\title{
Multi-stage constant-current charging protocol for a high-energy-density pouch cell based on a $622 \mathrm{NCM} /$ graphite system
}

\begin{abstract}
Fuqiang An, (D) *ab Rui Zhang, ${ }^{\mathrm{c}}$ Zhiguo $\mathrm{Wei}^{\mathrm{c}}$ and Ping $\mathrm{Li}^{\star a}$
A novel multi-stage-constant-current (MS-CC) charging protocol, which charges high-energy-density lithium-ion cells (LICS) at a faster rate, is presented herein. In this work, the $0-80 \%$ state of charge (SoC), according to the maximum charging rate, yields acceptable results for different SoCs, and the charging process is divided into three parts. Twelve groups of experiments are designed under the desired conditions of avoiding lithium plating and using a charging time of less than $36 \mathrm{~min}$, and $1.5 \mathrm{C}$ constant current charging is used as a comparison experiment. The full pouch cells are dismantled, and the lithium deposition after $1.5 \mathrm{C}$ charging is more extensive than that after the MS-CC charging protocol. In addition, the capacity retention for $1.5 \mathrm{C}$ charging is $95.7 \%$, while those for the $12 \mathrm{MS}-\mathrm{CC}$ charging protocol groups are within the range of $99.5-100.0 \%$ after the 300 th cycle at $25{ }^{\circ} \mathrm{C}$. When the temperature is $25{ }^{\circ} \mathrm{C}$ and $50{ }^{\circ} \mathrm{C}$, the capacity retention of the $12 \mathrm{MS}-\mathrm{CC}$ charging protocol groups remains similar, but when the temperature drops to $10{ }^{\circ} \mathrm{C}$, the capacity retention decreases except for the $2.0-1.5-0.9 \mathrm{C}$ and $1.8-1.5-0.9 \mathrm{C}$ groups. At the 510th cycle, the capacity retention of the $2.0-1.5-$ $0.9 \mathrm{C}$ and $1.8-1.5-0.9 \mathrm{C}$ groups is $99.6 \%$ and $99.9 \%$, respectively; the values of the other 10 groups are between $95.0 \%$ and $98.2 \%$. The excellent electrochemical performances of the MS-CC charging protocol may be due to the minimal damage of cell materials caused by the step-type high-rate charging process; thus, the degree of polarization is small. Furthermore, compared with the conventional constant constant-current (CC) charging procedure, MS-CC charging greatly shortens the charging time.
\end{abstract}

\section{Introduction}

With the rapid depletion of fossil fuels and severe environmental degradation, seeking alternative power sources is becoming imperative. ${ }^{1,2}$ Lithium-ion cells (LICs), one of the main energy storage devices, have become a topic of intense research focus because of their overwhelming advantages over other cells, such as higher energy density, longer cycle life and better eco-friendliness. Currently, LICs are widely applied to daily life, such as in portable electronic products, portable medical devices, and energy-saving industrial facilities.,4 Additionally, LICs are the most promising power sources for electric vehicles (EVs) and plug-in hybrid electric vehicles (PHEVs), which are likely to be the next generation of green transportation. ${ }^{5}$ The mass commercialization of EVs and PHEVs may be largely reliant on whether researchers can improve the energy and power densities of LICs and lower their cost. However, higher energy density has a trade-off with higher

${ }^{a}$ Beijing University of Science and Technology, No.30 Collage Road, Haidian District, Beijing, China. E-mail: liping@ustb.edu.cn

${ }^{b}$ Shanxi Changzheng Power Technology Co., Ltd., Shanxi, China

'Idrivetech Automobile Co., Ltd., No. 2 Nanqi Road, ChangPing District, Beijing, China power performance; considering the higher energy density requirements for the commercialization of LICs, it is critical to shorten the charging time in practice while ensuring the performance of the cells.

At present, the main charging protocol of commercial cells is the conventional constant current-constant voltage (CC-CV) charging protocol. The $\mathrm{CC}-\mathrm{CV}$ charging protocol includes two continuous steps:; one step is the constant current charging stage, which lasts until the cell voltage reaches the preset value (4.1 or $4.2 \mathrm{~V}){ }^{6,7}$ The other step is when the voltage reaches the preset value: the system is switched to constant voltage charging, and the current will gradually decrease to another preset value ${ }^{6,7}$ During the application of a constant voltage, the current slowly diminishes, which greatly extends the charging time. ${ }^{6,7}$ In addition, for the CC-CV protocol, using a high rate of charging for the LICs will lead to lithium plating in the high state of charge (SoC). When the rate of $\mathrm{Li}^{+}$embedding in the surface of the anode material is faster than the diffusion inside the material, $\mathrm{Li}^{+}$will accumulate on the surface of the anode electrode to form lithium metal. ${ }^{8-10}$ It is well known that lithium plating will affect the cycle performance and high/lowtemperature performance in LICs and can lead to safety accidents. To lengthen the span life and restrain lithium plating on 
anode electrodes in LICs, a variety of charging protocols have been developed. For example, continuously varying current charging, ${ }^{11,12}$ pulse current charging, ${ }^{13-15}$ boost charging, ${ }^{16}$ constant power charging ${ }^{\mathbf{1 7}}$ and multi-stage constant current charging $^{\mathbf{1 8 , 1 9}}$ protocols have been evaluated.

Sikha reported that the relationship between continuously varying current charging and time is a linear complex function, and the charging voltage of this method is always maintained under the cut-off voltage, thus realizing fast charging on the premise of not affecting the cell life. ${ }^{12}$ Pulse current charging, controlling the whole charging process by adjusting the current amplitude, pulse time, and pulse interval, can alleviate the polarization phenomenon and enhance the utilization rate of active materials, as well as improve the cycle performance. ${ }^{\mathbf{1 4}}$ Judy's group used the Taguchi orthogonal array method to determine the optimal parameters of pulse charging. Compared with the CC-CV protocol, the energy and charge efficiencies of the pulse charge are increased by approximately $11.3 \%$ and $1.5 \%$, respectively. ${ }^{20}$ The boost charging protocol refers to precharging a certain amount of charge with a large current in the initial charging stage (low SoC) and then switching to the $\mathrm{CC}-\mathrm{CV}$ procedure. Notten et al. reported that the boost charging method can fulfil the requirement of rapidly charging LICs without causing any deterioration for the cell, which can be charged to $30 \%$ within 5 min under the empty state. ${ }^{16}$ Although the above rapid charging protocols shorten the charging time, the lithium plating caused by high-rate charging has not been specifically studied. It is universally known that under the conditions of low temperature, high rate and high SoC, metal lithium formation can readily occur at the surface of the anode electrode. Nuclear magnetic resonance (NMR) technology and charge-discharge curve analysis are used to detect metal lithium in LICs. ${ }^{21-23}$ However, these methods all have certain limitations. For example, NMR technology has a relatively higher level of demand for samples (extremely thin, suitable size), and charge-discharge curve analysis cannot detect lithium oxide on the surface at low or high SoC. In this work, the MS-CC charging protocol is adopted to achieve the required rapid charging of LICs. This method can not only shorten the charging time but also extraordinarily improve the cycling performance compared with the high-rate constant current charging protocol. Furthermore, to observe the phenomenon of metal lithium formation on the anode surface, the most intuitive disassembly technology is applied. Although this technology may be destructive to the cells, it is the most practical for commercial LICs. The test processes and electrochemical properties of the as-prepared lithium-ion full pouch cells are discussed in detail.

\section{Experiment}

\subsection{Charging boundary determination}

Twenty-six commercially available full pouch cells, which were sorted from forty-five cells based on capacity, mass ACR and OCV measurements, were charged between 0 and $80 \%$ SoC. These cells are mainly composed of cathode (611 NCM, $\mathrm{LiNi}_{0.6} \mathrm{Co}_{0.6} \mathrm{Mn}_{0.2} \mathrm{O}_{2}$ ), anode (graphite), separators and electrolyte. The electrode loading for the anode was $110 \mathrm{~g} \mathrm{~m}^{-2}$ (one side), with $95.1 \%$ active material, 3.7\% binder (CMC/SBR) and $1.2 \%$ conductive carbon. The cathode loading was $190 \mathrm{~g}$ $\mathrm{m}^{-2}$ (one side), with $96.5 \%$ active material, $2 \%$ binder and $1.2 \%$ conductive carbon. The average energy density of these cells can be as high as $235 \mathrm{~W} \mathrm{~h} \mathrm{~kg}^{-1}$.

Combined with the actual charge requirement for EVs, charging more than $80 \%$ power in less than $40 \mathrm{~min}$ is acceptable. The SoC of $0-80 \%$ was separated into three parts, $0-30 \%$ SoC, $30-60 \%$ SoC and $60-80 \%$ SoC, and the metal lithium boundary of each part was evaluated (as shown in Table 1). The main reasons for dividing the $0-80 \%$ SoC into three parts are as follows: (1) low SoC charging with a high rate will not lead to deterioration of the cell materials; (2) a high SoC is prone to lithium plating, so this charging uses a small current; and (3) the charging time is less than 36 min. The maximum charging rates of each stage are determined by three experiments. In test 1 , cells are charged with $2.8 \mathrm{C}$ (0-30\% SoC), 2.5C (30-60\% SoC) and 1.5C (60-80\% SoC) and cycled five times in each stage. It is worth noting that in the second and third stages, the small current of $0.3 \mathrm{C}$ is used to charge the $30 \%$ and $60 \%$ SoC, respectively. To observe lithium deposition at the anode electrode interface, the cells are disassembled in the glove box after the cycling process. Test 1 shows that the three stages of the cells exhibit lithium deposition. Test 2 is designed to reduce the charge rate of three stages based on the results of test 1 . However, after disassembly of the cell, poor results are obtained, similar to those in test 1 . Therefore, the charge rates of the three stages are once again decreased to $2.2 \mathrm{C}, 1.9 \mathrm{C}$ and $0.9 \mathrm{C}$ for $0-30 \%, 30-60 \%$, and $60-80 \%$ SoC, respectively. After 5 cycles, there is no grey metallic lithium on the surface of separators. Finally, the maximum charging rates of the three stages are finally ascertained to be $2.2 \mathrm{C}, 1.9 \mathrm{C}$ and $0.9 \mathrm{C}$, respectively.

\subsection{Cycle performance}

The galvanostatic charge-discharge tests were performed on a Neware cell test system (Shenzhen, China) at different current densities between 2.5 and $4.25 \mathrm{~V}\left(v s . \mathrm{Li}^{+} / \mathrm{Li}\right)$. On the basis of charging boundary conditions, 12 groups of rapid charging schemes are established, and $1.5 \mathrm{C}$ continuous constant current charging is used as a reference experiment (two cells in each group). These charging schemes are shown in Table 2, and the test procedure of the MS-CC charging is schematically shown in Fig. 1. During the testing process, each stage is separated based on time, and an under-voltage and over-voltage protection program is set. To standardize all the cells, capacity calibration is performed before the rapid charging test. These cells are charged at $0.5 \mathrm{C}$ to $4.25 \mathrm{~V}$ and then discharged at $1 \mathrm{C}$ to $2.5 \mathrm{~V}$ for three cycles. To further eliminate the interference of temperature factors on the experimental results, the temperature changes in one cycle of the 13-group charging scheme are monitored during charging and discharging processes and then used to determine the shelving time of the charge-discharge process. During the process, the thermocouple is positioned in 
Table 1 Different SoC lithium plating boundary

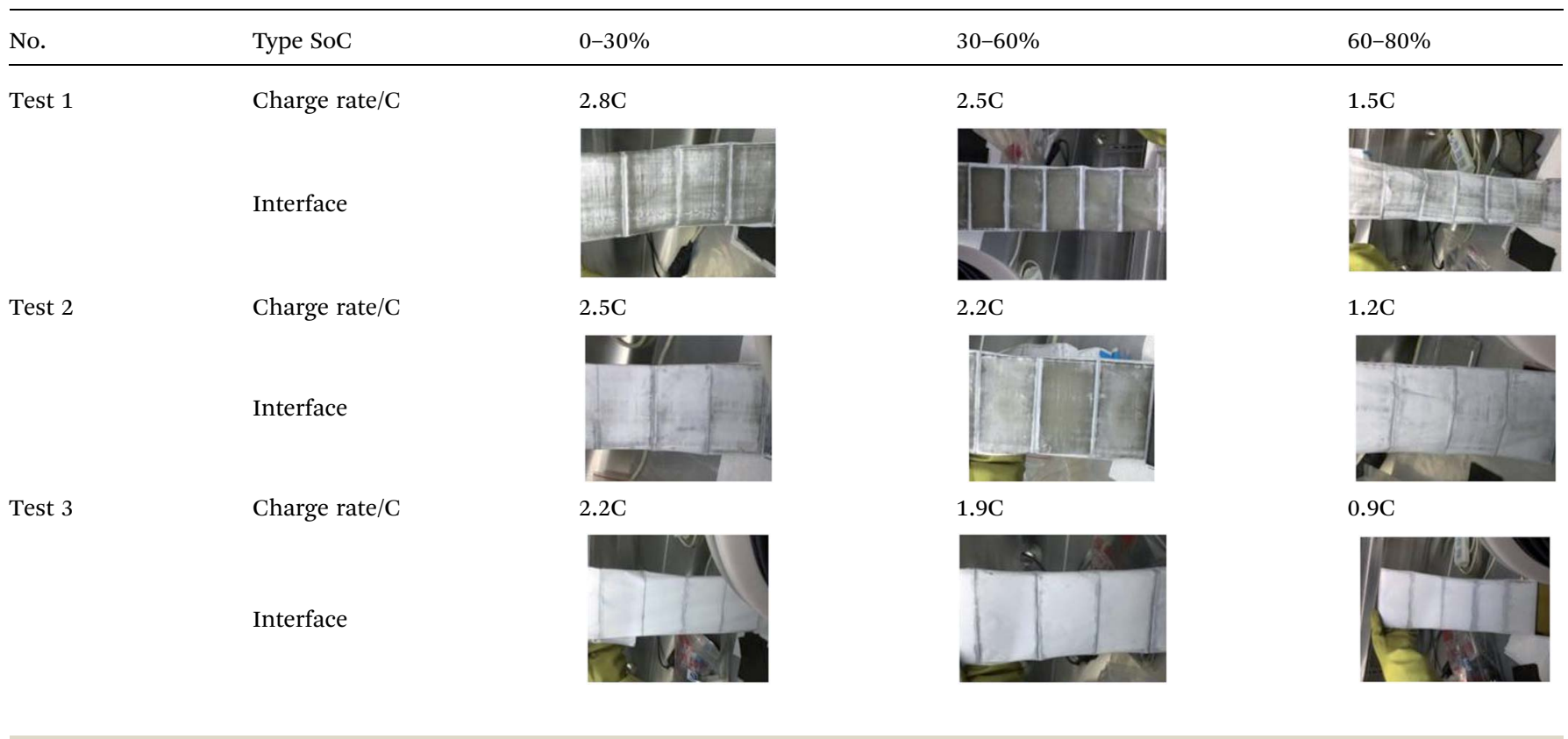

Table 213 groups charging scheme of 0 to $80 \%$ SoC

\begin{tabular}{lllll}
\hline Group & $0-30 \%$ SoC & $30-60 \%$ SoC & $60-80 \%$ SoC & Charge time $/ \mathrm{min}$ \\
\hline 1 & $2.2 \mathrm{C}$ & $1.9 \mathrm{C}$ & $0.9 \mathrm{C}$ & 31 \\
2 & $2.2 \mathrm{C}$ & $1.9 \mathrm{C}$ & $0.7 \mathrm{C}$ & 34.8 \\
3 & $2.2 \mathrm{C}$ & $1.7 \mathrm{C}$ & $0.9 \mathrm{C}$ & 32.1 \\
4 & $2.2 \mathrm{C}$ & $1.7 \mathrm{C}$ & $0.7 \mathrm{C}$ & 35.9 \\
5 & $2.2 \mathrm{C}$ & $1.5 \mathrm{C}$ & $0.9 \mathrm{C}$ & 33.5 \\
6 & $2 \mathrm{C}$ & $1.9 \mathrm{C}$ & $0.9 \mathrm{C}$ & 31.8 \\
7 & $2 \mathrm{C}$ & $1.9 \mathrm{C}$ & $0.7 \mathrm{C}$ & 35.61 \\
8 & $2 \mathrm{C}$ & $1.7 \mathrm{C}$ & $0.9 \mathrm{C}$ & 32.9 \\
9 & $2 \mathrm{C}$ & $1.5 \mathrm{C}$ & $0.9 \mathrm{C}$ & 34.3 \\
10 & $1.8 \mathrm{C}$ & $1.9 \mathrm{C}$ & $0.9 \mathrm{C}$ & 32.8 \\
11 & $1.8 \mathrm{C}$ & $1.7 \mathrm{C}$ & $0.9 \mathrm{C}$ & 33.9 \\
12 & $1.8 \mathrm{C}$ & $1.5 \mathrm{C}$ & $0.9 \mathrm{C}$ & 35.3 \\
13 & $1.5 \mathrm{C}$ & $1.5 \mathrm{C}$ & $1.5 \mathrm{C}$ & 32
\end{tabular}

the middle of the cells, and its accuracy is $0.5^{\circ} \mathrm{C}$. After charging, G1-G12 take $7 \mathrm{~min}$ to reach room temperature, G13 takes $15 \mathrm{~min}$ to drop to room temperature, and all cells need to be cooled room temperature for $10 \mathrm{~min}$ after discharging. The temperature changes of charging at different rates under different SoCs are listed in Table 3.

After the above pre-test, the 13 groups of cells are cycled at $25{ }^{\circ} \mathrm{C}, 50{ }^{\circ} \mathrm{C}$ and $10{ }^{\circ} \mathrm{C}$ with designed charge protocols, and the discharge rate is $1 \mathrm{C}$ for all the cells.

\subsection{Polarization characterization}

In an increment of every 100 cycles, the cycling tests are terminated, and the cells are brought to the fully charged state using a $0.5 \mathrm{C}$ CC-CV protocol, followed by impedance and ac resistance measurements. To explore the polarization characterization of the 13 charging scheme groups, electrochemical impedance spectroscopy (EIS) measurements were performed on an electrochemical workstation (VMP3, France) with an AC voltage of $5 \mathrm{mV}$ amplitude in the frequency range of $10^{5}$ to $10^{-2} \mathrm{~Hz}$.

The differential voltage $(\mathrm{d} Q / \mathrm{d} V)$ is used to differentiate the changes in the redox peaks. Fresh and aged cells were measured

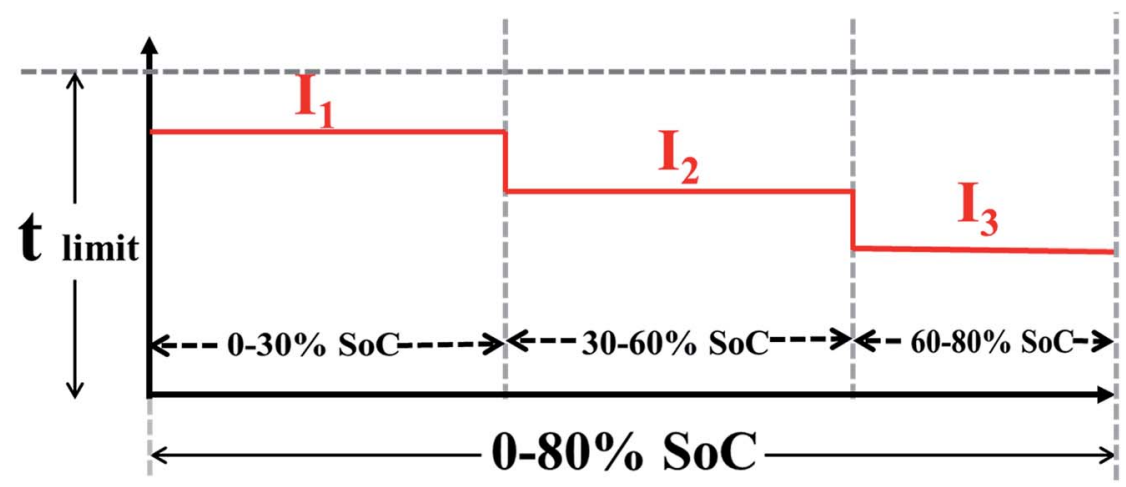

Fig. 1 Schematic illustrates the charging process of multi-stage constant current charging protocol. 
Table 3 The temperature changes of 13 groups charging scheme of charging-discharging

\begin{tabular}{|c|c|c|c|c|c|c|c|c|c|}
\hline & Pre-test temperature ${ }^{\circ} \mathrm{C}$ & \multicolumn{6}{|c|}{ Charging ${ }^{\circ} \mathrm{C}$} & \multicolumn{2}{|c|}{ Discharging ${ }^{\circ} \mathrm{C}$} \\
\hline G2: $2.2-1.9-0.7$ & 23.6 & 26.4 & 2.8 & 26.6 & 3 & 24.3 & 0.70 & 25.6 & 2 \\
\hline G3: $2.2-1.7-0.9$ & 23.8 & 26.5 & 2.7 & 26.4 & 2.6 & 24.7 & 0.90 & 25.9 & 2.1 \\
\hline G4: $2.2-1.7-0.7$ & 23.7 & 26.5 & 2.8 & 26.2 & 2.5 & 24.3 & 0.60 & 25.6 & 1.9 \\
\hline G7: 2-1.9-0.7 & 23.7 & 26 & 2.3 & 26.7 & 3 & 24.3 & 0.60 & 25.8 & 2.1 \\
\hline G8: $2-1.7-0.9$ & 23.3 & 25.7 & 2.4 & 26 & 2.7 & 24.5 & 1.20 & 25.4 & 2.1 \\
\hline G9: $2-1.5-0.9$ & 23.4 & 25.7 & 2.3 & 25.4 & 2 & 24.4 & 1.00 & 25.4 & 2 \\
\hline G10: $1.8-1.9-0.9$ & 24 & 25.9 & 1.9 & 26.6 & 2.6 & 25 & 1.00 & 25.8 & 1.8 \\
\hline G11: $1.8-1.7-0.9$ & 23.7 & 26 & 2.3 & 26.7 & 3 & 24.8 & 1.10 & 25.8 & 2.1 \\
\hline G12: $1.8-1.5-0.9$ & 23.7 & 25.6 & 1.9 & 25.6 & 1.9 & 24.6 & 0.90 & 25.6 & 1.9 \\
\hline
\end{tabular}

using the VMP3 system with $0.2 \mathrm{C}$ charge and discharge, and the data acquisition frequency was $1 \mathrm{~s}$.

\subsection{Analysis for post-mortem state}

To gain insight into the lithium plating phenomenon of the cells in the post-mortem state, the full pouch cells were disassembled in an argon-filled glove box with water and oxygen concentrations below 1 ppm.

\section{Results and discussion}

To investigate the electrochemical properties of the 13 charging scheme groups, the cycle performance and capacity recovery capabilities are tested at a voltage range of 2.5-4.25 V. Fig. 2a and $b$ show the capacity retention of the 13 charging scheme groups under different temperatures. The reason for applying different cycle temperatures in this work is to quickly screen out the optimal rapid charging combination at $0-80 \%$ SoC. It can be clearly seen from Fig. 2a that the capacity retention of multistage current charging slightly varies at $25{ }^{\circ} \mathrm{C}$ and $50{ }^{\circ} \mathrm{C}$, but when charging at $1.5 \mathrm{C}$ constant current (G13), the capacity retention of the 300th cycle is seriously attenuated at $25^{\circ} \mathrm{C}$. To make matters worse, the cells of the $1.5 \mathrm{C}$ constant current have a flatulence phenomenon after 300 cycles (Fig. 2d and e). After disassembling the $1.5 \mathrm{C}$ constant current charging cell, many impurities are observed on the anode electrode and separator, possibly due to the continuous charging at a high rate, which resulted in the production of metal lithium and reacted with the electrolyte (Fig. 2f). This result proves that the MS-CC charging protocol is more suitable for high-rate rapid charging than single high-rate constant current charging. The state of the charging cycles at $10{ }^{\circ} \mathrm{C}$ is shown in Fig. $2 \mathrm{~b}$. The capacity retention of all cells shows a downward trend, but the extents of decline for 2.0-1.5-0.9C (G9) and 1.8-1.5-0.9C (G12) are the smallest relative to the other 10 groups. The capacity retention of G9 and G12 are $99.6 \%$ and $99.9 \%$, respectively, whereas those of the other 10 groups are between $95.0 \%$ and $98.2 \%$ at the 510th cycle. The capacity retention of the capacity calibration for each 100 cycles of the 13 charging scheme groups is presented in Fig. 2c, in which the capacity retention of all cells gradually decreases as the number of cycles increases. Comparing the capacity retention of all cells, the decline rate of G13 is fastest, with $85.0 \%$, and those of G9 and G12 are the slowest (94.0 and $95.1 \%$, respectively). The above results further demonstrate that the MS-CC charging protocol is better than high-rate constant current charging for the rapid charging of LICs. In addition, after $36 \mathrm{~min}$, groups G9 and G12 have the best electrochemistry performance compared to the other 10 groups of rapid charging schemes, proving that the combination of charging rates is equally important.

The effect of the charging protocol on cell polarization is displayed in Fig. 3. Fig. 3a-c show the charge curves of the G3 and G12 groups under $60-80 \%$ SoC at the 1st, 300th, 500th and 510 th cycles. The polarization degree of cells is expressed by the voltage of the 300th, 500th and 510th cycles (corresponding to the voltage charged to $0.4 \mathrm{~A} \mathrm{~h}$ ) minus the voltage of the 1st cycle. It is calculated that the difference values of the 300th, 500th and 510th cycles of G12 are $-1.5 \mathrm{mV},-47.4 \mathrm{mV}$ and $161.5 \mathrm{mV}$, respectively, which are much lower than those of G3, with $10.8 \mathrm{mV}$ (300th), -24.4 mV (500th) and $202.2 \mathrm{mV}$ (510th). In addition, it is clear that the difference values of the 300th, 500th and 510th cycles of G9 and G12 are lower than those of the other groups; the difference value of the 300th cycle of G13 is the largest, which proves that the MS-CC charging protocol is less destructive to cell materials and that the polarization degrees of G9 and G12 are the lowest. The differential voltage $(\mathrm{d} Q / \mathrm{d} V)$ curves can elucidate some of the locations and types of fade mechanisms in LICs. ${ }^{24,25}$ The peaks on the $\mathrm{d} Q / \mathrm{d} V$ curves originate from phase transitions, and the translation of the peak position represents the change in the cell internal resistance. ${ }^{26}$ Fig. 3d shows the $\mathrm{d} Q / \mathrm{d} V$ curves of the 13 charging scheme groups and a new cell, in which the curve of the new cell has two oxidation peaks and two reduction peaks. Because this experiment is a full pouch cell test, the curve shows the common peaks of the cathode and anode materials. The curves of the other 13 groups are similar to those of the new cell, indicating that there is no phase transition during the cycle. As the 

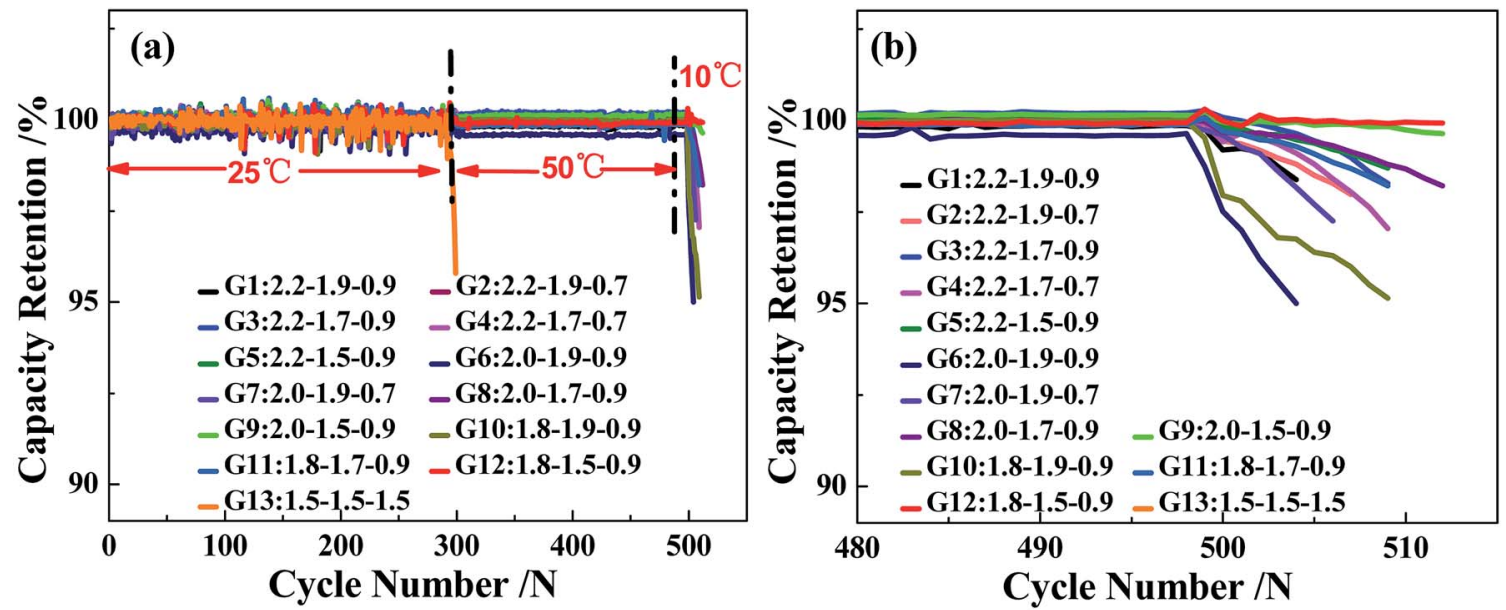
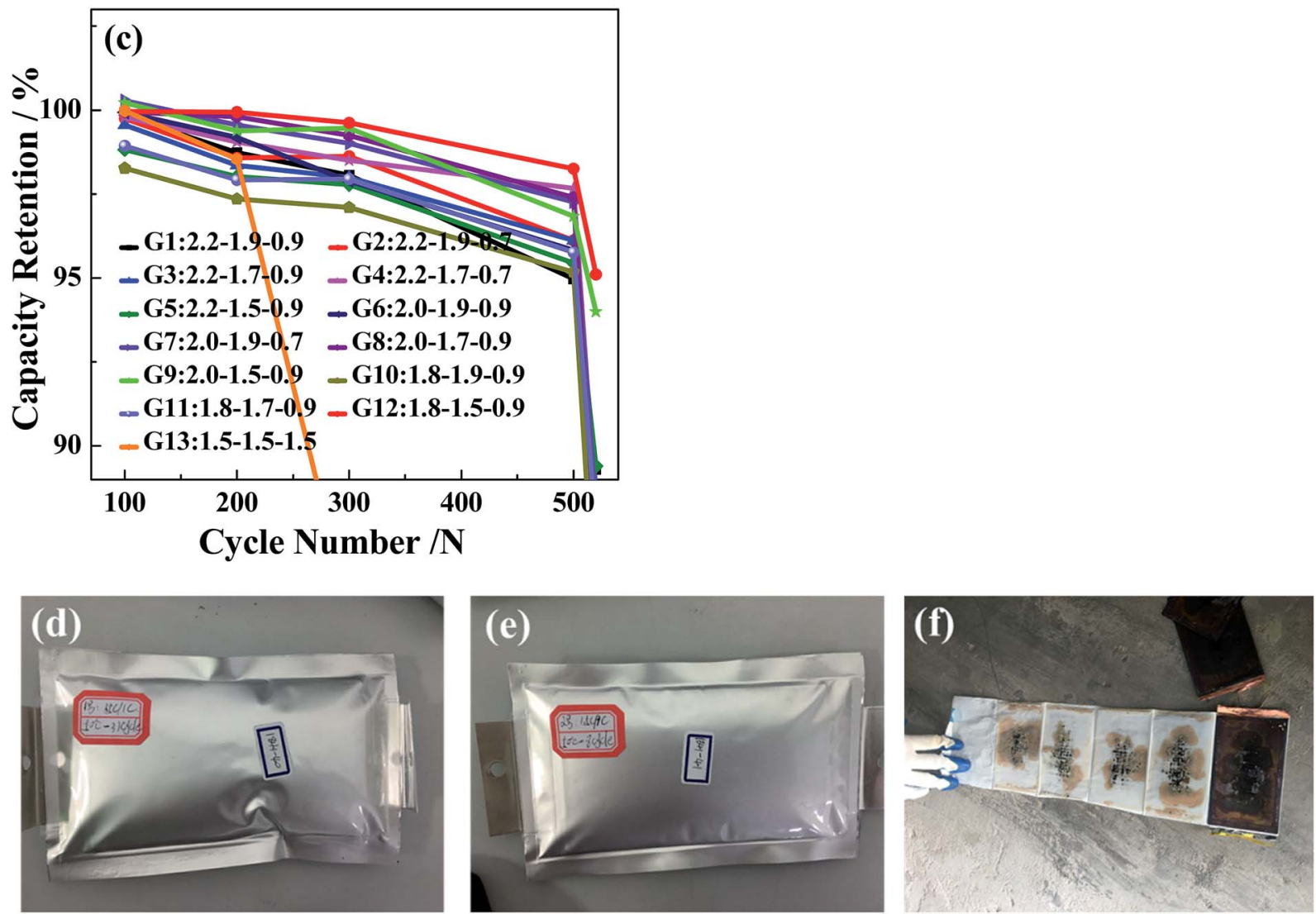

Fig. 2 The different temperatures of 13 groups charging scheme ( $\mathrm{a}$ and b) the capacity retention, (c) the capacity calibration, 1.5C constant current chargeable cells after 300 cycles ( $d$ and e), and disassemble appearance image (f)

benchmark curve of the new cell, the oxidation peaks of G9 and G12 shift to the right the least distance, illustrating that their internal resistance is smallest in the 13 charging scheme groups. In addition, the peak intensity reflects the content of active materials, and the peak intensity will weaken with the loss of active materials. ${ }^{27}$ It can be seen from Fig. $3 \mathrm{~d}$ that the peak intensity of the 13 charging scheme groups is lower than that of the new cell, but G13 has the lowest peak intensity relative to the other groups, which indicates that high-rate constant current charging will lead to additional loss of active materials. Furthermore, the peak strengths of G9 and G12 are the strongest among the 12 rapid charging scheme groups, suggesting that the charging rate of these two groups is beneficial to the rapid charging of LICs.

To investigate the effects of the 13 charging scheme groups on the cell electrochemical performance, EIS measurements were carried out. Fig. 4 shows the Nyquist plots of the 13 charging scheme groups after the 300th, 500th and 510th cycles under $50 \%$ SoC. As seen in Fig. $4 \mathrm{a}$ and b, all the impedance spectra are composed of a single semicircle in the highfrequency region and an inclined line in the low-frequency region. ${ }^{28-30}$ Generally, the semicircle is closely related to the 

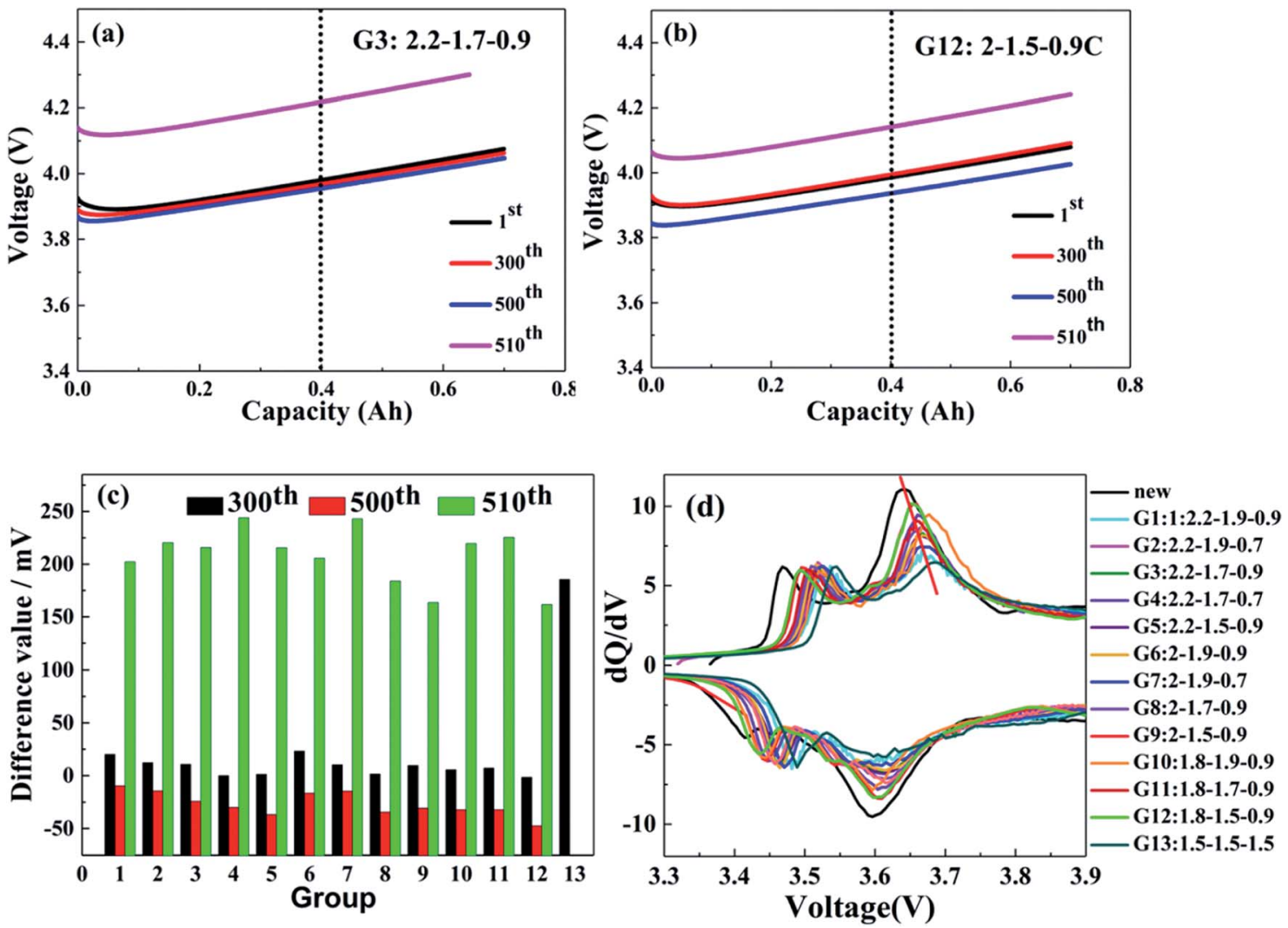

Fig. $360-80 \%$ charging curves of G12 (a) and G3 (b), the difference value of 13 groups charging scheme (c), dQ/dV curves of 13 groups charging scheme and new cell (d).

charge transfer resistance $\left(R_{\mathrm{ct}}\right)$, which reflects the electrode reaction kinetics, and the inclined line represents the Warburg impedance $\left(Z_{\mathrm{w}}\right)$, which is caused by the diffusion of lithium ions into the active material. ${ }^{31}$ The intercept of the semicircle with the $Z^{\prime}$-axis in the high-frequency region refers to unremunerative ohmic resistance $\left(R_{\mathrm{s}}\right)$, which includes the resistance of the electrolyte, Li metal anode and $\mathrm{Al}$ foil current collector. ${ }^{32}$ Based on the abovementioned, the equivalent circuit for the electrodes is shown in Fig. 4b and c, and the related simulated electrochemical parameters are tabulated in Table 4. As shown in Fig. 4 a, the G13 cell delivers a $R_{\mathrm{ct}}$ value of $0.0267 \Omega$, which is significantly higher than that for the other 12 groups, ranging from 0.0166 to $0.0211 \Omega$; this result shows that the multi-stage charging protocol attains a smaller electrochemical polarization. After 510 cycles, there are two semicircles that appear in the Nyquist plots of the samples (Fig. 4c). The semicircle located in the high-frequency region is assigned to the impedance resulting from the generation of SEI films $\left(R_{\mathrm{f}}\right)$, while another neighbouring semicircle in the mid-frequency region is ascribed to the $R_{\mathrm{ct}^{3}}{ }^{33,34}$ It can be observed from Fig. $4 \mathrm{~b}$ and $\mathrm{cthat}$ the $R_{\mathrm{ct}}$ values of G9 and G12 increased slowly as the number of cycles increased compared with the other 10 groups. G9 and G12 possess lower $R_{\mathrm{ct}}$ values, which may be attributed to the fact that the current combination of these two groups does less damage to the cell materials during the charging process.

To realize the rapid charging technology of LICs, it is necessary to determine the maximum current that the cells can withstand under different SoC conditions (the lithium
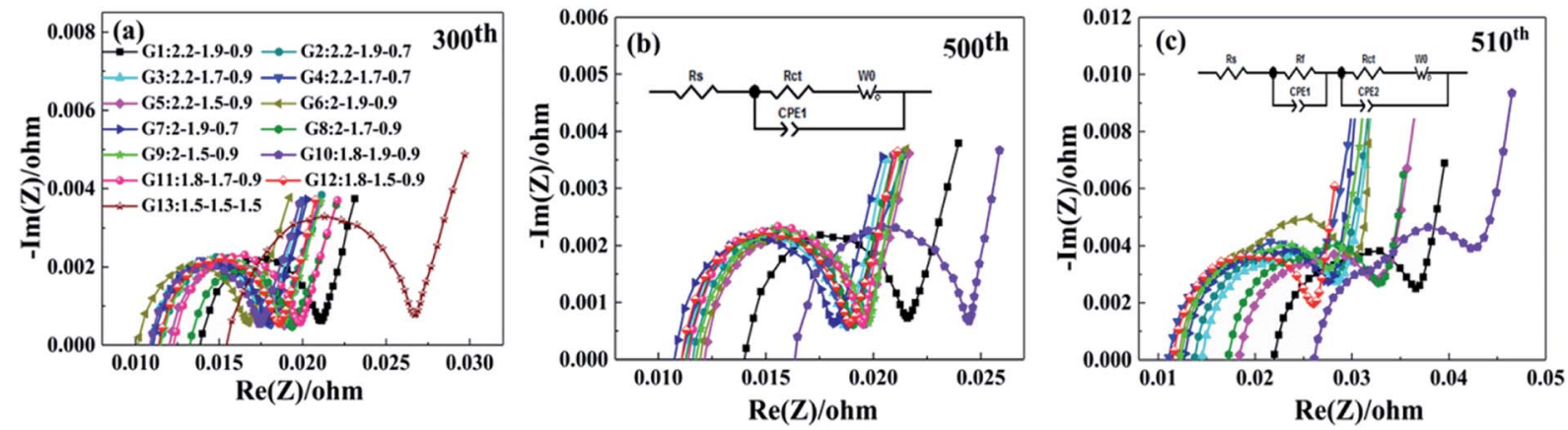

Fig. 4 The ElS curves the 13 groups charging scheme different cycle numbers of 300th (a), 500th (b) and 510th (c). 
Table 4 Impedance indexes simulated from the equivalent circuits

\begin{tabular}{|c|c|c|c|c|c|c|c|c|c|c|c|c|c|c|}
\hline Cycle number & Resistance & G1 & G2 & G3 & G4 & G5 & G6 & G7 & G8 & G9 & G10 & G11 & G12 & G13 \\
\hline \multirow[t]{2}{*}{300} & $R_{\mathrm{S}}(\mathrm{m} \Omega)$ & 13.9 & 11.5 & 11.0 & 11.2 & 12.1 & 10.2 & 11.1 & 13.3 & 11.5 & 11.0 & 12.4 & 11.5 & 15.5 \\
\hline & $R_{\mathrm{ct}}(\mathrm{m} \Omega)$ & 21.0 & 18.6 & 17.7 & 18.0 & 18.9 & 16.6 & 17.9 & 19.3 & 18.7 & 17.3 & 19.7 & 18.5 & 26.7 \\
\hline & $R_{\mathrm{ct}}(\mathrm{m} \Omega)$ & 21.7 & 19.0 & 18.7 & 18.8 & 19.5 & 19.4 & 18.2 & 19.0 & 19.7 & 24.4 & 19.4 & 18.8 & - \\
\hline \multirow[t]{2}{*}{510} & $R_{\mathrm{S}}(\mathrm{m} \Omega)$ & 22.0 & 13.7 & 14.5 & 11.0 & 18.4 & 12.1 & 12.7 & 17.2 & 12.3 & 26.1 & 12.8 & 11.6 & - \\
\hline & $R_{\mathrm{f}}(\mathrm{m} \Omega)$ & 29.7 & 22.6 & 23.3 & 18.6 & 27.2 & 20.4 & 20.2 & 23.6 & 20.6 & 31.9 & 24.1 & 19.4 & - \\
\hline
\end{tabular}

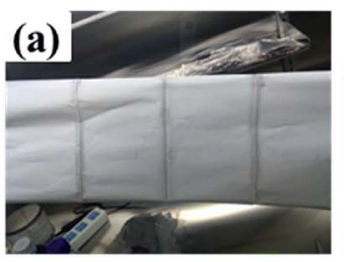

New cell

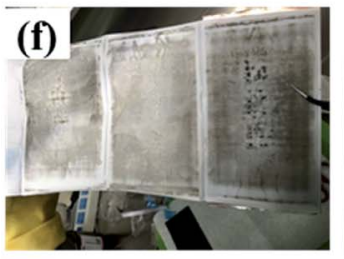

2.2C-1.5C-0.9C

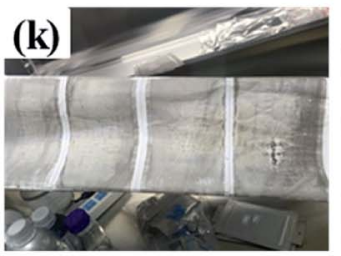

1.8C-1.9C-0.9C

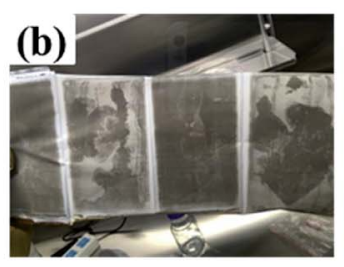

2.2C-1.9C-0.9C

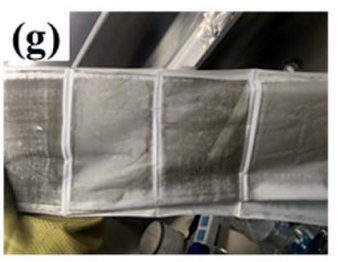

$2 \mathrm{C}-1.9 \mathrm{C}-0.9 \mathrm{C}$

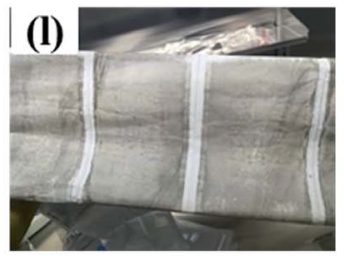

1.8C-1.7C-0.9C

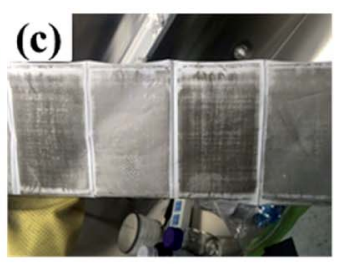

2.2C-1.9C-0.7C
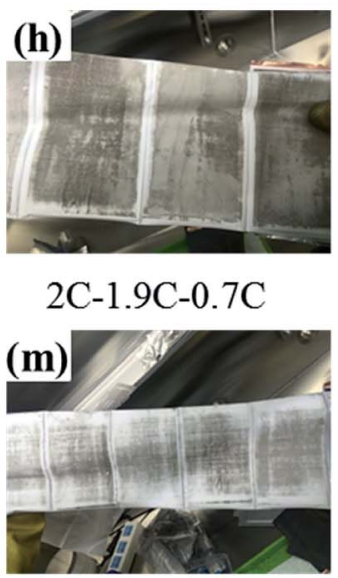

$1.8 \mathrm{C}-1.5 \mathrm{C}-0.9 \mathrm{C}$

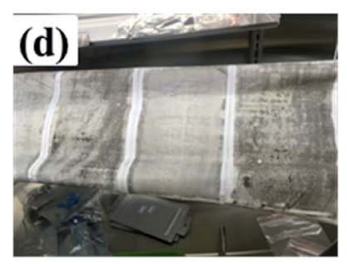

2.2C-1.7C-0.9C

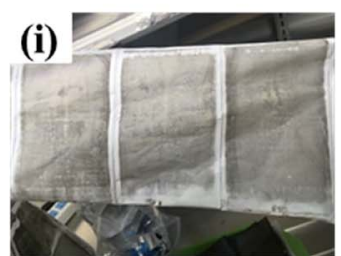

$2 \mathrm{C}-1.7 \mathrm{C}-0.9 \mathrm{C}$

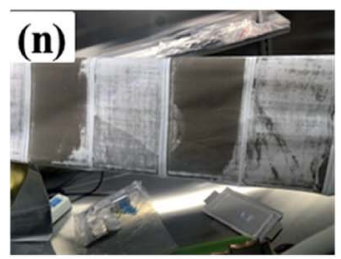

1.5C-1.5C-1.5C

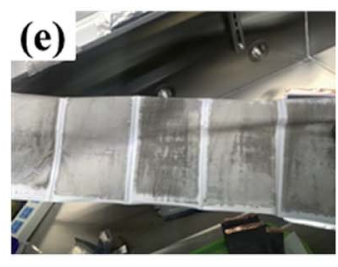

2.2C-1.7C-0.7C

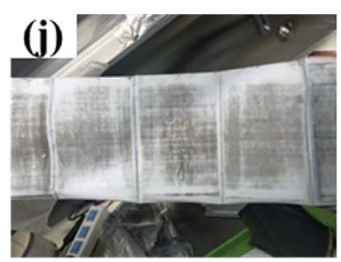

$2 \mathrm{C}-1.5 \mathrm{C}-0.9 \mathrm{C}$

Fig. 5 Graphic of separators' surface for 13 groups experiments after cycled with different charge rates.

plating boundary). Comparisons of metal lithium formation at different charging rates are made by observing the surface of all the cell separators. As shown in Fig. 5, metal lithium (grey part) exists on the surface of all the separators except those of the new cells (which have only been calibrated for capacity). It is observed that the lithium plating degree shown in Fig. 5j (G9) and $m$ (G12) is clearly lower than that of the other groups (Fig. $5 \mathrm{~b}-\mathrm{i}, \mathrm{k}, \mathrm{l}$ and $\mathrm{n}$ ). It is obvious that carbon is bound to the surface of the separator for the b, $c$ and $n$ series.

\section{Conclusions}

The key factor in realizing the rapid charging technology of LICs is to circumvent the phenomenon of lithium plating. To overcome this problem, a MS-CC charging protocol for higher energy density (235 $\mathrm{W} \mathrm{h} \mathrm{kg}^{-1}$ ) pouch cells with a $611 \mathrm{NCM} /$ graphite system was carried out in this work. To quickly screen out the optimal combination of charging rate at $0-80 \%$ SoC, the cells were tested at $25{ }^{\circ} \mathrm{C}, 50{ }^{\circ} \mathrm{C}$ and $10{ }^{\circ} \mathrm{C}$. By comparing the 13 charging scheme groups, it is concluded that G9 (2.0-1.5-0.9C) and G12 (1.8-1.50.9C) have the best electrochemical performance after 510 cycles. The interfacial lithium plating at the separator surface is the most minor for these two groups compared with the other 11 groups, indicating that MS-CC charging is more suitable for high-rate fast charging. In addition, the capacity retention values of G9 and G12 are $99.6 \%$ and $99.9 \%$, while those of the other 10 groups are in the range of 95.0-98.2\% at the 510th cycle. Similarly, G9 and G12 have the lowest polarization, which is expressed by evaluating the difference values of the same point during the cycle at $60-80 \%$ SoC. The results indicate that these favourable electrochemical properties can be mainly attributed to the suitable combination of charging rate at different SoCs, which can decrease polarization and restrain the precipitation of lithium metal during the charging process. In addition, the MS-CC charging not only improves the cycle performance but can also shorten the charging time. 


\section{Conflicts of interest}

There are no conflicts to declare.

\section{Acknowledgements}

This work is supported by the China Postdoctoral Science Foundation under grant number 2018M631335; supported by the Fundamental Research Funds for the Central Universities under grant number FRF-TP-18-024A1; and supported by the Shanxi Province Science and Technology Major Project under grant number 20181102005.

\section{References}

1 F. X. Wang, X. Wu, C. Li, et al., Nanostructured positive electrode materials for post-lithium ion batteries, Energy Environ. Sci., 2016, 9, 3570-3611.

2 S. Chu, Y. Cui and N. Liu, The path towards sustainable energy, Nat. Mater., 2017, 16, 16-22.

3 S. F. Wu, W. X. Wang, M. C. Li, L. J. Cao, F. Lu, M. Y. Yang, Z. Y. Wang, Y. Shi, B. Nan, S. C. Yu, Z. F. Sun, Y. Liu and Z. G. Lu, Highly durable organic electrode for sodium-ion batteries via a stabilized $\alpha$-C radical intermediate, Nat. Commun., 2016, 7, 13318.

4 D. P. Cao, C. L. Yin, D. R. Shi, Z. W. Fu, J. C. Zhang and C. L. Li, Cubic Perovskite Fluoride as Open Framework Cathode for Na-Ion Batteries, Adv. Funct. Mater., 2017, 27, 1701130.

5 S. Hy, H. Liu, M. Zhang, D. Qian, B.-J. Hwang and Y. S. Meng, Performance and Design Considerations for Lithium Excess Layered Oxide Positive Electrode Materials for Lithium Ion Batteries, Energy Environ. Sci., 2016, 9, 1931-1954.

6 M. Xu, R. Wang, B. Reichman and X. Wang, Modeling the effect of two-stage fast charging protocol on thermal behavior and charging energy efficiency of lithium-ion batteries, J. Energy Storage, 2018, 20, 298-309.

7 F. B. Spingler, W. Wittmann, J. Sturm, B. Rieger and A. Jossen, Optimum fast charging of lithium-ion pouch cells based on local volume expansion criteria, J. Power Sources, 2018, 393, 152-160.

8 Y. Gao, J. Jiang, C. Zhang, W. Zhang, Z. Ma and Y. Jiang, Lithium-ion battery aging mechanisms and life model under different charging stresses, J. Power Sources, 2017, 356, 103-114.

9 C. Bolsinger and K. P. Birke, Effect of different cooling configurations on thermal gradients inside cylindrical battery cells, J. Energy Storage, 2019, 21, 222-230.

10 Z. Zeng, W.-I. Liang, H.-G. Liao, H. L. Xin, Y.-H. Chu and H. Zheng, Visualization of Electrode-Electrolyte Interfaces in $\mathrm{LiPF}_{6} / \mathrm{EC} / \mathrm{DEC}$ Electrolyte for Lithium Ion Batteries via in Situ TEM, Nano Lett., 2014, 14, 1745-1750.

11 S. K. Chung, A. A. Andriiko and A. P. Mon'Ko, On charge conditions for Li-ion and other secondary lithium batteries with solid intercalation electrodes, J. Power Sources, 1999, 79, 205-211.
12 G. Sikha, P. Ramadass and B. S. Haran, Comparison of the capacity fade of Sony US 18650 cells charged with different protocols, J. Power Sources, 2003, 122, 67-76.

13 M. F. Hasan, C. Chen and C. E. Shaffer, Analysis of the implications of rapid charging on lithium-ion battery performance, J. Electrochem. Soc. India, 2015, 162, A1382A1395.

14 J. Li, E. Murphy and J. Winnick, The effects of pulse charging on cycling characteristics of commercial lithium-ion batteries, J. Power Sources, 2001, 102, 302-309.

15 X. W. Zhao, G. Y. Zhang and L. Yang, A new charging mode of Li-ion batteries with $\mathrm{LiFePO}_{4} / \mathrm{C}$ composites under low temperature, J. Therm. Anal. Calorim., 2001, 104, 561-567.

16 P. Notten, J. Veld and J. Beek, Boostcharging Li-ion batteries: A challenging new charging concept, J. Power Sources, 2005, 145, 89-94.

17 S. S. Zhang, The effect of the charging protocol on the cycle life of a Li-ion battery, J. Power Sources, 2006, 161, 1385-1391.

18 Y. H. Liu, J. H. Teng and Y. C. Lin, Search for an optimal rapid charging pattern for lithium-ion batteries using ant colony system algorithm, IEEE Trans. Ind. Electron., 2005, 52, 1328-1336.

19 Y. Liu, C. Hsieh and Y. Luo, Search for an optimal five-step charging pattern for Li-ion batteries using consecutive orthogonal arrays, IEEE Trans. Energy Convers., 2011, 26, 654-661.

20 J. M. Amanor-Boadu, A. Guiseppi-Elie and E. SánchezSinencio, Search for Optimal Pulse Charging Parameters for Li-ion Polymer Batteries Using Taguchi Orthogonal Arrays, IEEE Trans. Ind. Electron., 2018, 11, 8982-8992.

21 J. Arai, Y. Okada, T. Sugiyama, M. Izuka, K. Gotoh and K. Takeda, In situ Solid State 7Li NMR Observation of Lithium Metal Deposition during Overcharge in Lithium Ion Battery, ECS Trans., 2014, 62, 159-187.

22 M. Petzl and M. A. Danzer, Nondestructive detection, characterization, and quantification of lithium plating in commercial lithium-ion batteries, J. Power Sources, 2014, 254, 80-87.

23 T. Waldmann and M. Wohlfahrt-Mehrens, Effects of rest time after Li plating on safety behavior-ARC tests with commercial high-energy 18650 Li-ion cells, Electrochim. Acta, 2017, 230, 454-460.

24 X. Li, J. Jiang, L. Y. Wang, D. Chen, Y. Zhang and C. Zhang, A capacity model based on charging process for state of health estimation of lithium ion batteries, Appl. Energy, 2016, 177, 537-543.

25 G. Wang, L. Yi, R. Yu, X. Wang, Y. Wang, Z. Liu, B. Wu, M. Liu, X. Zhang, X. Yang, X. Xiong and M. Liu, $\mathrm{Li}_{1.2} \mathrm{Ni}_{0.13} \mathrm{Co}_{0.13} \mathrm{Mn}_{0.54} \mathrm{O}_{2}$ with Controllable Morphology and Size for High Performance Lithium-Ion Batteries, ACS Appl. Mater. Interfaces, 2017, 9, 25358-25368.

26 K. Ando, T. Matsuda and D. Imamura, Degradation diagnosis of lithium-ion batteries with a $\mathrm{LiNi}_{0.5} \mathrm{Co}_{0.2} \mathrm{Mn}_{0.3} \mathrm{O}_{2}$ and $\mathrm{LiMn}_{2} \mathrm{O}_{4}$ blended cathode using dV/dQ curve analysis, J. Power Sources, 2018, 390, 278-285. 
27 S. Liu, L. Xiong and C. He, Long cycle life lithium ion battery with lithium nickel cobalt manganese oxide (NCM) cathode, J. Power Sources, 2014, 261, 285-291.

28 R. Zhang, X. Y. Wang, S. Y. Wei, X. Wang, M. Liu and H. Hu, Iron fluoride microspheres by titanium dioxide surface modification as high capacity cathode of Li-ion batteries, $J$. Alloys Compd., 2017, 719, 331-340.

29 G. Wang, L. L. Yi, R. Z. Yu, X. Y. Wang, Y. Wang, Z. S. Liu, B. Wu, M. Liu, X. H. Zhang, X. K. Yang, X. H. Xiong and M. L. Liu, $\mathrm{Li}_{1.2} \mathrm{Ni}_{0.13} \mathrm{Co}_{0.13} \mathrm{Mn}_{0.54} \mathrm{O}_{2}$ with Controllable Morphology and Size for High Performance Lithium-Ion Batteries, ACS Appl. Mater. Interfaces, 2017, 9, 25358-25368. 30 X. Huang, H. Yu, J. Chen, Z. Y. Lu, R. Yazami and H. H. Hng, Ultrahigh Rate Capabilities of Lithium-Ion Batteries from 3D Ordered Hierarchically Porous Electrodes with Entrapped Active Nanoparticles Configuration, Adv. Mater., 2014, 26, 1296-1303.
31 R. Ruffo, S. S. Hong, C. K. Chan, R. A. Huggins and Y. Cui, Impedance analysis of silicon nanowire lithium ion battery anodes, J. Phys. Chem. C, 2015, 113, 11390-11398.

32 C. Li, X. P. Han, F. Y. Cheng, Y. X. Hu, C. C. Chen and J. Chen, Phase and composition controllable synthesis of cobalt manganese spinel nanoparticles towards efficient oxygen electrocatalysis, Nat. Commun., 2015, 6, 7345-7352.

33 L. Zheng, L. Liu, X. Zhou and Y. Guo, An Electrochemical Impedance Spectroscopy (EIS) Study of Zndoped $\mathrm{Li}\left(\mathrm{Ni}_{1 / 3} \mathrm{Co}_{1 / 3} \mathrm{Mn}_{1 / 3}\right) \mathrm{O}_{2}$ Cathode Materials in the First Delithiation Process, Adv. Mater. Res., 2014, 833, 50-55. 34 B. Lu, B. Ma, X. Deng, B. Wu, Z. Wu, J. Luo, X. Wang and G. Chen, Dual Stabilized Architecture of Hollow Si@TiO ${ }_{2} @ C$ Nanospheres as Anode of High-Performance Li-Ion Battery, Chem. Eng. J., 2018, 6, 178-216. 